\title{
Rapid climate change-related growth decline at the southern range edge of Fagus sylvatica
}

\author{
ALISTAIR S. JUMP ${ }^{1}$, JENNY M. HUNT and JOSEP PEÑUELAS \\ Unitat d'Ecofisiologia CSIC-CEAB-CREAF, CREAF (Centre de Recerca Ecològica i Aplicacions Forestals), \\ Universitat Autònoma de Barcelona, 08193, Bellaterra, Catalonia, Spain
}

\begin{abstract}
Studies on Fagus sylvatica show that growth in populations toward the southern limit of this species' distribution is limited strongly by drought. Warming temperatures in the Mediterranean region are expected to exacerbate drought where they are not accompanied by increases in precipitation. We studied levels of annual growth in mature F. sylvatica trees over the last half-century in the Montseny Mountains in Catalonia (northeast Spain). Our results show significantly lower growth of mature trees at the lower limit of this species' distribution when compared with trees at higher altitudes. Growth at the lower Fagus limit is characterized by a rapid recent decline starting in approximately 1975 . By 2003 , growth of mature trees had fallen by $49 \%$ when compared with predecline levels. This is not an age-related phenomenon, nor is it seen in comparable populations at higher altitudes. Analysis of climate-growth relationships suggests that the observed decline in growth is a result of warming temperatures and that, as precipitation in the region has not increased, precipitation is now insufficient to ameliorate the negative effects of increased temperatures on tree growth. As the climateresponse of the studied forest is comparable with that of $F$. sylvatica forests in other southern European regions, it is possible that this growth decline is a more widespread phenomenon. Warming temperatures may lead to a rapid decline in the growth of rangeedge populations and a consequent retreat of the species distribution in southern Europe. Assessment of long-term growth trends across the southern range edge of F. sylvatica therefore merits further attention.
\end{abstract}

Keywords: BAI, basal area increment, climate change, drought, European beech, geographical range, Mediterranean, range edge

Received 16 September 2005; revised version received 23 February 2006 and accepted 24 May 2006

\section{Introduction}

Changes in growth and reproduction are among the primary responses of trees to environmental variation. In parallel with long-term changes in climate, we expect to see long-term trends in tree growth and reproduction, with consequent impacts on population size and the species' distribution. However, the population-level response of trees to climate is difficult to investigate directly, owing to the long lifespan of individuals and often extended juvenile (nonreproductive) periods (Brubaker, 1986). As individuals of many tree species

Correspondence: Alistair S. Jump, tel. +44 1904 432999, fax +44 1904 432998, e-mail: aj523@york.ac.uk

${ }^{1}$ Present address: Environment Department, The University of York, Heslington, York YO10 5DD, UK.

(C) 2006 The Authors

Journal compilation (C) 2006 Blackwell Publishing Ltd may survive for many hundreds of years, assessment of geographical range changes is complicated by their longevity. Adult trees may persist at the edges of the species' distribution long after the climate has become unsuitable for their successful reproduction (LaMarche, 1973; Pigott \& Huntley, 1978). Although there are now numerous reports of ongoing climate-related range changes of woody species (see e.g. Wardle \& Coleman, 1992; Meshinev et al., 2000; Sturm et al., 2001; Kullman, 2002, 2003; Lloyd \& Fastie, 2003; Peñuelas \& Boada, 2003; Sanz-Elorza et al., 2003), these are heavily biased toward the leading edge of the species' distribution. As recruitment is generally more sensitive to climate than mortality, an increase in reproduction at the expanding range edge of a tree species' distribution occurs more rapidly than an increase in the mortality of established trees at the retreating edge (LaMarche, 1973; 
Lloyd, 1997). Consequently, it may take decades or even centuries longer to detect range changes at the retreating edge than at the expanding edge, if the same survey-based methods are used to analyse both.

If long-term changes in the growth of established trees are occurring at the range edge, then the trees themselves will record these. Variation in tree growth results in variation in the width of the annual growth rings that are laid down during each growing season. However, ring width in mature trees declines with age, thus, if a declining growth trend is suspected, it may be impossible to investigate it on the basis of changes in ring width alone (Phipps \& Whiton, 1988). The conversion of radial increment (ring width) into basal area increment (BAI) overcomes this problem (Phipps \& Whiton, 1988; LeBlanc, 1990b; Pedersen, 1998). Unlike ring width, age-related trends in unstandardized BAI are generally positive, culminating in a linear phase of high mature BAI that can be maintained for many decades (Phipps \& Whiton, 1988; LeBlanc, 1990b). Therefore, a negative trend in BAI is a strong indication of a true decline in tree growth (LeBlanc, 1990b; Pedersen, 1998).

At the low-altitude and low-latitude range margins of tree species, there is often a negative relationship between growth and growing season temperature and a positive relationship with precipitation, as a consequence of the limiting effects of low water availability on growth and direct effects of extreme temperatures on physiological processes (see e.g. Brubaker, 1986 and references therein; Takahashi et al., 2001 and references therein; Grace et al., 2002; Makinen et al., 2002; Dittmar et al., 2003). The limitation of growth by drought at the low-altitude, low-latitude range edge may have profound consequences for the persistence of populations where current increases in temperature are not matched by increases in precipitation. Investigation of patterns of long-term growth has the potential to identify growth declines long before these become evident as changes in the species distribution.

Recent work by Peñuelas \& Boada (2003) has detected an upward shift of Fagus sylvatica L. forest in the Montseny Mountains (Catalonia, NE Spain) promoted by the warming climate and changing land use. At its lower altitudinal limit, they report that this species is declining by the gradual isolation and degradation of F. sylvatica populations and their replacement by Quercus ilex L. (holm oak). Additional work on F. sylvatica at Montseny shows a strong negative impact of drought and high summer temperatures on growth (Gutierrez, 1988). The high plasticity of the growth of adult trees enables them to slow growth to survive periods of poor growing conditions; normal growth usually resumes when favourable conditions return (Brubaker, 1986).
Consequently, climatic factors that have a positive or negative effect on annual growth may not be translated into long-term growth trends, unless they are increasing in severity or in frequency over time. Although recent climatic warming has increased the length of the growing season for many species in the Montseny region (Peñuelas et al., 2002), Peñuelas \& Boada (2003) report increased discoloration and defoliation of $F$. sylvatica crowns at lower elevations; these are typical symptoms of tree decline (Duchesne et al., 2003).

Given the warming trend reported for the Montseny region and the associated distributional changes of F. sylvatica, we aimed to determine whether there is any evidence for changes in recent growth trends of mature individuals. We assessed the effects of climate change on long-term growth of this species by analysing growth trends against yearly climatic variables. Our data provide additional information on whether the decline of isolated populations of F. sylvatica at low altitudes involves a general decline of adult trees or whether this decline is more likely to result from regenerative failure in combination with the death of remaining old adults. The localized competitive replacement of F. sylvatica by more drought-tolerant species is important in understanding and predicting the fate of this species in the Montseny region. However, significant climate-related growth decline at lower altitudes could have serious implications for the persistence of this species throughout much wider areas of its southern European range-margin.

\section{Materials and methods}

\section{Study sites and sample preparation}

This work was conducted at the southern edge of the distribution of F. sylvatica in Europe in the Montseny Mountains, $50 \mathrm{~km} \mathrm{NNW}$ of Barcelona (Catalonia, NE Spain; Fig. 1). F. sylvatica forest occurs in the temperate zone of the mountains, typically above 1000 metres above sea level (ma.s.l.). Below the temperate zone the vegetation is Mediterranean, dominated by $Q$. ilex forest. F. sylvatica forms the treeline on the highest peaks of the region (Turó de l'Home and Les Agudes, 1712 and $1706 \mathrm{~m}$ a.s.l., respectively). The F. sylvatica forest is naturally occurring uneven-aged high forest that has been managed at low intensity by the selective removal of large trees coupled with natural regeneration from seed. However, the impact of forest management on the upper and lower limits of the F. sylvatica forest has been low (Peñuelas \& Boada, 2003). Soils of the Montseny F. sylvatica forest are typically Dystric Regosols and Dystric Cambisols established over schist and granodiorite lithology. The most typical forest community is 


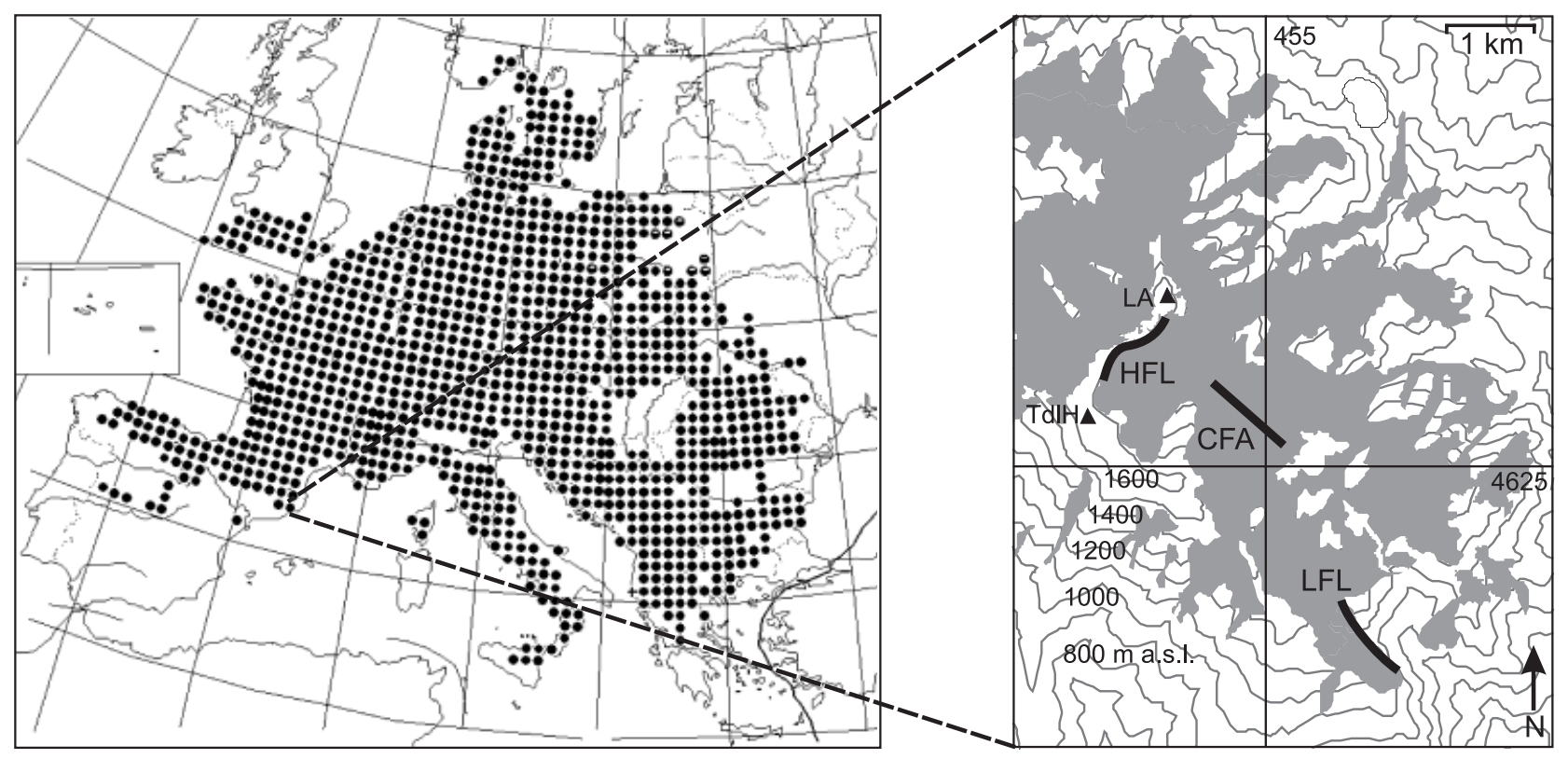

Fig. 1 Left: native distribution of Fagus sylvatica (reproduced from Jalas \& Suominen (1976), by permission of the Committee for Mapping the Flora of Europe and Societas Biologica Fennica Vanamo). Right: location of study sites in relation to F. sylvatica distribution in the study area. F. sylvatica distribution is shown in grey. Study sites: HFL, upper treeline (high Fagus limit); CFA, central forest area; LFL, low Fagus limit. Bold lines show the distribution of individuals sampled at each site. Principal peaks are marked with a triangle. TdlH, Turó de l'Home; LA, Les Agudes. Grid lines are numbered with UTM coordinates in km.

the Luzulo-Fagetum with less common areas of HeleboroFagetum. A detailed description of the vegetation of Montseny and its altitudinal zonation is presented by Bolòs (1983).

Climate data (mean annual temperature and total annual precipitation) were taken from the Turó de l'Home meteorological station (1712 ma.s.l.), directly above our highest sample site ( 1640 ma.s.l.). Mean annual temperature and total annual precipitation records were available for the period 1952-2003 (Fig. 2). Missing data from the monthly Turó de l'Home climate records for the period 1958-2003 were interpolated from the meteorological stations at Cardedeu (195 ma.s.l., $17 \mathrm{~km}$ SSW of Turó de l'Home), Fabra observatory (413 ma.s.l., $48 \mathrm{~km}$ SSE) and Roquetes (55 ma.s.l., $194 \mathrm{~km}$ WSW) for temperature data and Cardedeu and Fabra observatory for precipitation using MET (Holmes, 2001).

Fifteen mature, dominant or codominant F. sylvatica trees without signs of physical damage were selected over a distance of $1 \mathrm{~km}$ at each of three altitudinal sites within the largest area of continuous forest. The sites were located in closed forest in areas without signs of recent disturbance and situated at the upper treeline (identified here as the high Fagus limit or HFL site), the central forest area (CFA site) and low Fagus limit (LFL site; Fig. 1). The HFL and LFL sites were on steep slopes whereas the CFA site was predominantly on level

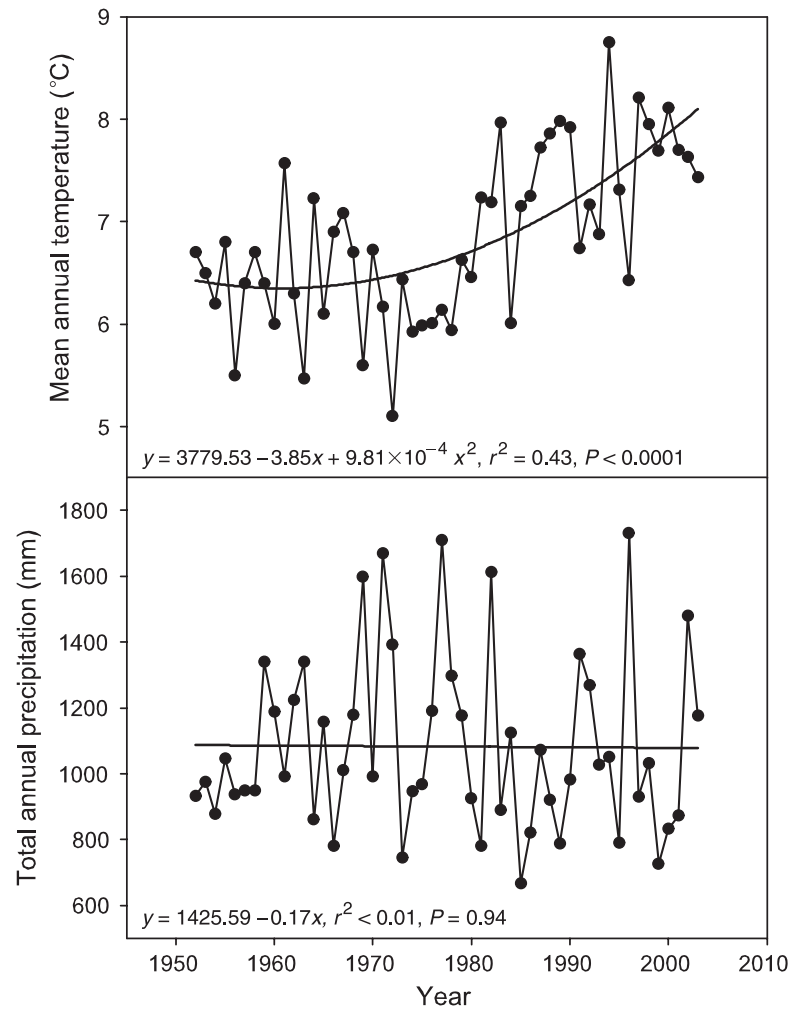

Fig. 2 Mean annual temperature and total annual precipitation at Turó de l'Home during the period 1952-2003. Temperatures show a significant warming trend beginning in the mid-1970s whereas no trend is seen for precipitation. 
ground with deeper, less stony soils around the Santa Fe River. All sites were situated on the southeast side of the Turó de l'Home-Les Agudes ridge.

Two or three increment cores were taken from each tree at breast height $(1.3 \mathrm{~m})$ using a $4.3 \mathrm{~mm}$ increment borer. Diameter at breast height was also recorded. Cores were air-dried and fixed into specially constructed grooved boards. Samples were sanded to prepare them for tree-ring analysis using standard dendroecological methods. Prepared samples were then scanned at 1600 d.p.i. using a flatbed scanner and saved as .jpg files. Ring width was measured to an accuracy of $0.001 \mathrm{~mm}$ using CooRecorder v2.3.13 (Larsson, 2003a). Preliminary matching of cores taken from the same tree was performed in CDendro v4.1.1. (Larsson, 2003b). Data files were then converted into decadal format using routines FMT and EDRM of the Dendrochronology Program Library (Holmes, 2001). Cross-dating accuracy was checked using COFECHA v6.06P (Holmes, 2001) and sections of any core that were a poor match with the COFECHA master series for each site were identified. Where poor matching of correctly dated segments resulted from twisted, compressed or decayed wood, these were excluded from the analysis. Ring width for each year was averaged between the cores taken from each tree to produce a final ring width series for each individual. One tree at both the CFA and LFL was excluded from the analysis as these displayed complacent ring-width series (little variation between years) and therefore cross-dated poorly.

Ring width was converted into tree BAI according to the following standard formula:

$$
\mathrm{BAI}=\pi\left(R_{n}^{2}-R_{n-1}^{2}\right)
$$

where $R$ is the radius of the tree and $n$ is the year of tree ring formation.

To examine the mean growth trend of the dominant and codominant canopy trees for each site, BAI for each year was averaged over all individuals at each site. BAI series for dominant and codominant trees in mature stands typically show a period of early growth suppression (suppression phase) before a rapid increase in annual basal area growth (release phase). BAI may continue to increase in mature healthy mature trees (Phipps \& Whiton, 1988; LeBlanc, 1990a, b; Duchesne et al., 2002, 2003; Fekedulegn et al., 2003; Muzika et al., 2004), or stabilize (LeBlanc et al., 1992), but it does not show a decreasing trend until trees begin to senesce (LeBlanc, 1990a; Duchesne et al., 2002, 2003). During the suppression and release phases, growth is strongly affected by variation in light levels and is thus not easily compared between trees. Consequently, we focus only on variation between levels of growth during the mature phase of growth, marked by the abrupt change in slope after the release phase in our study.

BAI values were also used to estimate age at breast height where none of the cores reached the centre of the tree. After determination of BAI for the full length of the core, a central area of the tree cross-section remained with known area but unknown age. This area was divided by average BAI for the first recorded 15 years of tree growth to give an estimate of the number of years taken to reach this size. This estimated value was added to the number of years of growth recorded for the core to provide an approximate age at breast height.

Tree ring data from each core are usually standardized to remove long-term growth trends and maximize the common climatic signal between trees (Cook et al., 1990). However, for this study it is precisely these long-term growth trends that we were interested in. Consequently, we worked with mean unstandardized BAI values across all trees at each site for each year. These provide interpretable yearly levels of growth rather than a standardized index and display growth trends clearly. They provide the information we seek, but at the expense of the loss of detailed information on climate. Given this low climatic resolution of unstandardized BAI, we analysed the effects of climate on long-term growth using mean annual climate, rather than monthly climatic values as used in dendroecological studies based on ring width. Where we have used a standardization procedure, this was done only to homogenize the variance of data to allow their direct comparison.

\section{Statistical analysis}

Mean BAI chronologies for each site were smoothed by the application of a 9-year running average to highlight growth trends while retaining their variability. We used the postrelease inflection point of the 9-year running average to mark the point at which the mature phase begins at each site in our study (Fig. 3). Individual chronologies were visually assessed to ensure that individual trees had reached mature BAI levels by the year indicated by the inflection point of the mean chronology for each site. As the inflection point corresponded to a peak of growth, mature BAI data were analysed from the following year to avoid this peak biasing growth trends away from the null expectation of non-negative mature growth. All statistical analyses use single-year mature BAI data for each site and not smoothed data.

Regression analysis was conducted using SigmaPlot 2002 v8.0 (SPSS Inc., Chicago, IL, USA). All other statistical tests were performed using SPSS for Mac v11.0.2 (SPSS Inc.). The earlier onset of the mature phase 


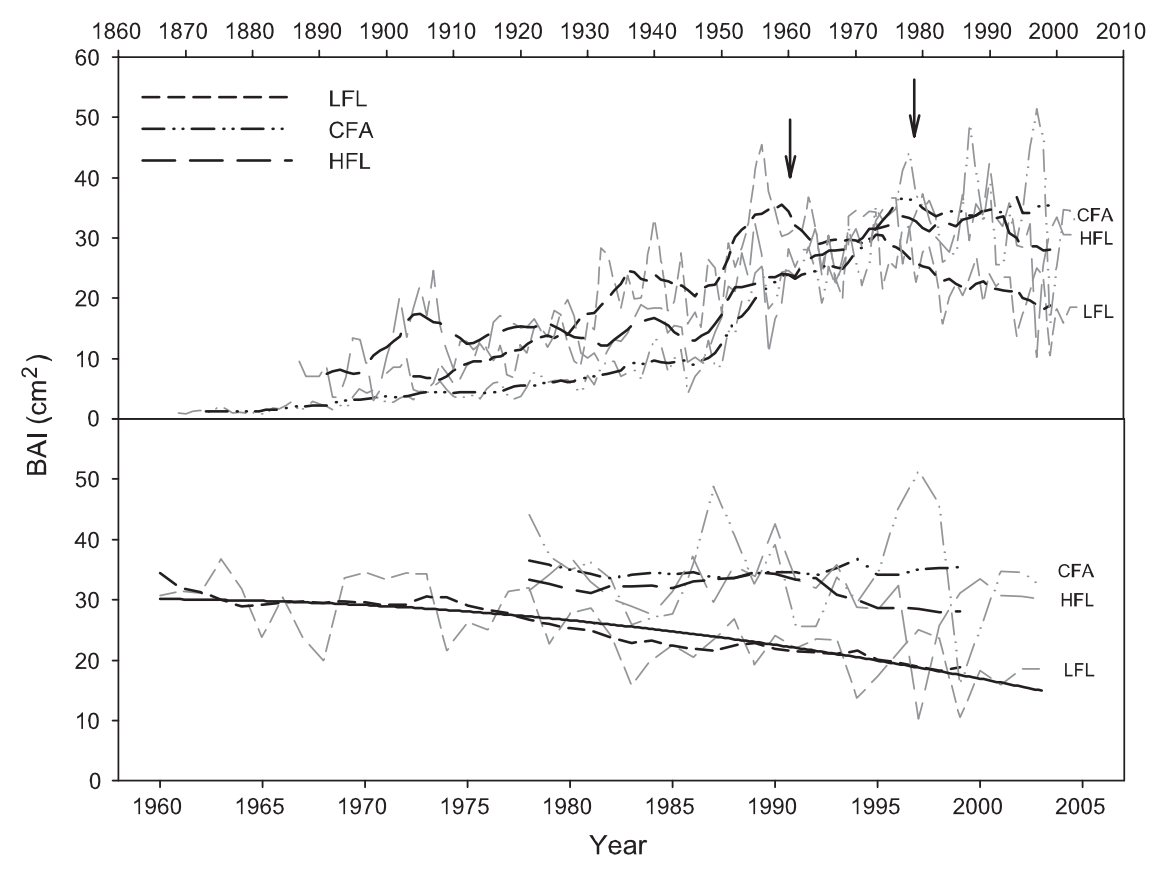

Fig. 3 Mean Fagus sylvatica basal area increment for three forest sites differing in altitude. Yearly data are represented by feint lines; trends are highlighted by a 9-year running average in bold. Sites are abbreviated as Fig. 1. Top: full basal area increment (BAI) chronology showing initial suppression phase before increase to mature tree levels. Arrows indicate the beginning of the mature phase of growth at different sites [left: low Fagus limit (LFL); right, central forest area and high Fagus limit]. Bottom: temporal trends in mature BAI at each site. The significant declining trend of BAI at the LFL site is represented by the solid line $\left(y=-29565+30.22 x-7.71 \times 10^{-3} x^{2}\right.$, $\left.r^{2}=0.50, P<0.0001\right)$.

in the LFL trees led to different sample sizes (number of years growth) between the three sites (LFL $n=44$, CFA $n=26$, HFL $n=26$ ). ANOVA was used to test for differences between mean mature BAI at each site. To facilitate comparison, samples at each site were compared for identical periods (1) the 26 years common to all three chronologies and (2) the initial 26 years of the mature phase of growth. This allowed us to control for any unexpected age-related effects leading to differences in growth between sites. When using ANOvA, a priori $t$-test comparisons (not assuming equal variance) were specified to test differences between individual means. ANOVA is relatively robust to unequal variance between samples if sample sizes are constant, however, as there were very large differences in the variance of age and diameter data between samples, the nonparametric (Kruskal-Wallace) test equivalent was used in these comparisons. Linear regression was used to identify significant temporal trends in climate, BAI of individual trees over the 26 years of mature BAI common to all three chronologies and for the average chronology at each site. We assessed first-order autocorrelation (AC) of model residuals in climatic and mature BAI regression analyses using the Durbin-Watson statistic (d) (Durbin \& Watson, 1951) and the correlation coefficient $r_{\mathrm{AC}}$ calculated according to the formula: $r_{\mathrm{AC}}=1-(d / 2)$.
Inconclusive values of $d$ were treated as indicating significant autocorrelation $(P<0.05)$. Where $d$ indicated significant autocorrelation, we reduced the number of degrees of freedom (df) for each test according to the approximate effective sample size $\left(N_{\text {eff }}\right)$, calculated according to the formula: $N_{\text {eff }} \approx N\left(1-r_{\mathrm{AC}}\right) /\left(1+r_{\mathrm{AC}}\right)$, where $N$ is the sample size (Quenouille, 1952). Treating inconclusive values of $d$ as indicating significant autocorrelation could introduce a Type II error into our results. However, in no case where $d$ was inconclusive did the adjusted $\mathrm{df}$ alter the test conclusion in comparison with the nonadjusted $\mathrm{df}$.

For correlation analyses of the relationship between BAI and climate, current year mean annual temperature and total annual precipitation were calculated for period beginning October of the previous year and ending with September of the current year. Previous year climate was summarized for the 12 months immediately preceding this period. This procedure avoids relating growth to climate in the months after leaf fall when growth has ceased. Pearson's product-moment correlation $(r)$ was calculated to identify relationships between BAI and yearly climatic variables and to test for relationships between tree age and diameter and BAI trend and between tree diameter and individual tree mean mature BAI. 
To allow direct visual comparison of temporal trends in BAI and related climatic variables, temperature, precipitation and BAI data were standardized to give a standard deviation of 1 and a mean of 0 by subtracting the sample mean from each value of $x$ and then dividing it by the sample standard deviation.

\section{Results}

\section{Altitudinal differences in the growth of F. sylvatica}

Figure 3 shows that the suppression phase appears to have been less severe at the upper treeline than in the central forest area. At the LFL site, the release phase began much earlier than at higher altitudes, therefore coverage of the suppression phase at the LFL is poor. Likewise, the mature phase began earlier at the LFL than at higher altitudes. There was no significant difference in the mean age of trees at each site (KruskalWallace test, $\left.\chi^{2}=0.01, \mathrm{df}=2, P=0.99\right)$ or between tree diameter (Kruskal-Wallace test, $\chi^{2}=0.96, \mathrm{df}=2$, $P=0.62)$.

Figure 3 shows that whereas mean annual mature BAI was very similar at the HFL and CFA, the trees of the LFL showed a very different pattern. Starting in approximately 1975, growth dropped rapidly at the lower Fagus limit from a mean value of $29.4 \mathrm{~cm}^{2}$ for the period $1960-1975$ to $14.9 \mathrm{~cm}^{2}$ in 2003 - a fall in growth of $49 \%$ over a period of 28 years (as indicated by the regression line in Fig. 3). This is evidenced by the significant quadratic relationship between BAI and growth year in the LFL trees $\left(r^{2}=0.50, P<0.0001\right)$. No significant relationship between mature BAI and growth year was seen at either of the other sample altitudes (CFA: $P=0.71$; HFL: $P=0.17$ ), therefore there is no evidence for any increasing or decreasing growth trend of trees at higher altitudes after they reached maturity in approximately 1978. The significant negative relationship between year of growth and BAI at the LFL persisted if the regression included only the first 26 years of the mature phase in order to compare identical sample sizes between each altitudinal group, $\left(r^{2}=0.25\right.$, $P=0.009$, not shown). Tests of the Durbin-Watson statistic (d) revealed no significant first-order autocorrelation in temporal trends of climate or mean mature BAI at the LFL or HFL $(P>0.05)$. Only mean mature BAI at the CFA showed significant autocorrelation among the model residuals $\left(d=1.23, P<0.05, r_{\mathrm{AC}}=0.385\right)$. When assessing mature BAI trend in individual trees, $d$ was significantly different from 0 in $40 \%$ and inconclusive in $19 \%$ of individual tests.

Within each stand, the variability in BAI trend among trees was high, as evidenced by the minimum and maximum slope values for the 1978-2003 period shown in Table 2. At the individual tree level, the majority of trees at both the HFL and CFA showed stable (no trend) or positive trends in mature tree BAI. This situation was reversed at the LFL where the majority of trees showed declining BAI and none showed a positive trend (Table 2). Mature BAI slope of individual trees was not related to tree diameter $(r=-0.10, P=0.55)$, but showed a marginally significant negative correlation with estimated tree age $(r=-0.29, P=0.06)$.

Average yearly growth over the 1978-2003 period was significantly different between the three forest altitudes (ANOVA: $F_{2,61}=29.58, P<0.001$ ) but this difference lay only in paired contrasts involving the LFL. There was no significant difference between mean BAI at the HFL and CFA during this period. When comparisons were made between sites for the first 26 years of the mature phase (comparing the LFL during the years 1960-1985 with the HFL and CFA during the years 1978-2003) the same pattern was evident (ANOVA: $F_{2,61}=6.41, P=0.003$; Table 2 ). When calculated over all individual trees, mature tree BAI averaged over the period 1978-2003 showed a significant relationship with tree diameter $(r=0.56, P<0.001)$.

\section{BAI-climate relationships}

When comparable sample sizes were considered for all three mature BAI chronologies (for the period 19782003), LFL BAI showed a significant negative correlation with temperature in the current and previous year of growth. Significant correlations between BAI and yearly climate were absent at the CFA and HFL (Table 3). When the full 44 years of the mature LFL BAI chronology were analysed, LFL BAI was also correlated positively with both current and previous year precipitation, although the relationship between LFL BAI and precipitation remained weaker than between LFL BAI and temperature.

Unstandardized mean temperature and precipitation for the 1952-2003 period at Turó de l'Home are presented in Fig. 2. There was a clear warming trend of mean annual temperature over this period, beginning in the mid-1970s $\left(r^{2}=0.43, P<0.0001\right)$, whereas no such trend existed for precipitation $\left(r^{2}<0.01, P=0.94\right)$. The relationship between LFL mature BAI and current year temperature is shown in Fig. 4a. The relationship with previous year mean temperatures, which exhibit even higher correlations with BAI (Table 3), is identifiable from this figure. In Fig. 4a, current year temperature and LFL BAI track each other very closely over the period analysed. Extreme mean annual temperatures often coincide with and overlap values of high or low growth. It is apparent that the main decline in LFL BAI began in approximately 1975, in parallel with increasing 


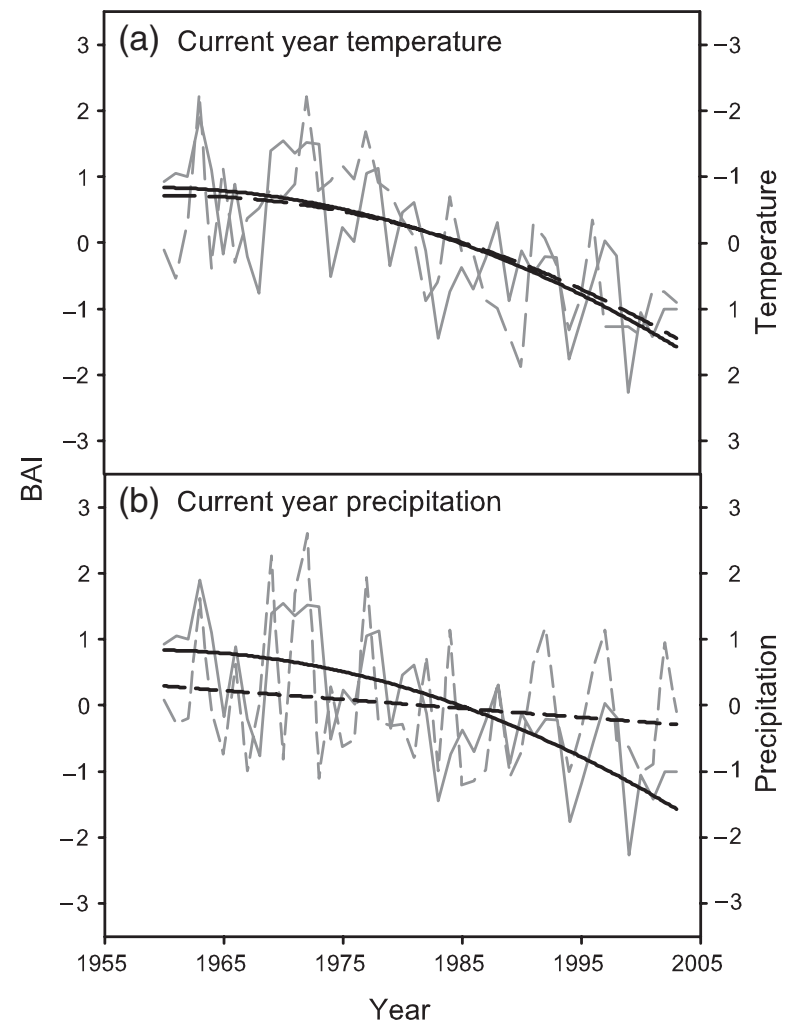

Fig. 4 Temporal trends in standardized current-year climate variables (dashed lines) and standardized mean mature tree basal area increment (BAI) (solid lines) at the low Fagus limit. (a) Mean annual temperature; (b) total annual precipitation. (a) The parallel trend in BAI and temperature is highlighted by the regression lines (BAI: $y=-4697.01+4.80 x-1.22 \times 10^{-3} x^{2}$, $r^{2}=0.50, \quad P<0.0001$; temperature: $y=4702.95-4.80 x+1.22 \times$ $\left.10^{-3} x^{2}, r^{2}=0.43, P<0.0001\right)$. b, Precipitation shows no temporal trend with BAI (BAI: regression as in (a); precipitation: $\left.y=26.85-0.014 x, r^{2}=0.03, P=0.26\right)$. Annual climate is based on a 12-month period beginning with October of the previous year. Note: The temperature axis is inverted to facilitate comparison with BAI, peaks on the temperature plot therefore represent low temperatures.

mean annual temperature. The standardized chronology for LFL mature BAI and standardized current year total precipitation is presented in Fig. 4b. Unlike the temperature and LFL BAI chronologies in Fig. 4a, the precipitation and LFL BAI chronologies do not track each other consistently well. Agreement between them is good initially, but as BAI is declining whereas precipitation shows no temporal trend, they diverge in recent years. Consequently, although peaks of precipitation often coincide with peaks of BAI or precede them by a year, recent peaks of standardized BAI are usually far lower than peaks of standardized precipitation. Lag effects of previous season conditions are evident in Fig. 4 where extreme climate years precede low or high
BAI by 1 year (e.g. temperature: 1964-1965, 1982-1983, 1996-1997; precipitation: 1967-1968, 1969-1970, 19771978) illustrating that both current year and previous year temperatures have a strong impact on levels of growth in the current year.

\section{Discussion \\ Temporal trends in $B A I$}

Trees at the HFL and CFA show a similar pattern of BAI to that reported for Liriodendron tulipifera (yellow poplar), Quercus prinus (chestnut oak), Q. rubra (northern red oak) and Acer rubrum (red maple) by Fekedulegn et al. (2003) and for the closely related measure of annual volume increment (AVI) in Picea rubens (red spruce) by LeBlanc (1990a, b) and LeBlanc et al. (1992) (Fig. 3). Following low BAI during the suppression phase, BAI shows a rapid increase during release before the slope of the curve is reduced as mature tree levels of growth are attained. This reduction in the gradient of the slope marks the beginning of the mature phase in our study (Fig. 3) and is a likely consequence of competition between mature canopy trees (LeBlanc 1990a, b). In our study, F. sylvatica maintains steady mean mature BAI at the HFL and CFA, comparable with mature tree AVI in P. rubens in the study reported by LeBlanc et al. (1992). However, in many species BAI continues to increase with age in mature trees (Phipps \& Whiton, 1988; LeBlanc, 1990a, b; Duchesne et al., 2002, 2003; Fekedulegn et al., 2003; Muzika et al., 2004) in some cases showing no evidence of the reduction in slope that LeBlanc (1990a, b) associates with canopy closure.

In contrast with the trees at the CFA and HFL, the LFL trees show a consistent decline of mature tree BAI over the last 28 years of our study. Declining BAI (negative slope) is not an expected consequence of tree maturation (LeBlanc et al., 1992). At least up to 200 years after release from suppression in P. rubens (LeBlanc et al., 1992) and up to 350 years in Quercus alba (white oak; Phipps \& Whiton, 1988) there is no evidence of negative BAI trends in healthy trees. Therefore, negative BAI trend is a strong indicator of a true decline in tree growth (Phipps \& Whiton, 1988; LeBlanc, 1990a, b; Duchesne et al., 2002, 2003). Prolonged BAI decline is naturally associated with tree senescence (LeBlanc, 1990a; Duchesne et al., 2002, 2003) and a good indicator of impending death (Pedersen, 1998). BAI may decline in response to a variety of stresses including competition (Duchesne et al., 2002), insect outbreaks and drought (Pedersen, 1998; Hogg et al., 2002), atmospheric pollution (Duchesne et al., 2002; Muzika et al., 2004) 
or other unidentified atmospheric stresses (Phipps \& Whiton, 1988; LeBlanc, 1990a; LeBlanc et al., 1992).

\section{BAI decline and temperature}

In our study, mature BAI trend of individual trees shows a marginally significant declining trend with increasing tree age $(r=-0.29, P=0.06)$. As most negative individual BAI trends occur at the LFL this may indicate that older trees are more susceptible to growth decline. Given the similar mean age and history of the three stands we studied and the similar stand structure of the three sites (Table 1), the declining mean mature BAI trend at the LFL cannot be interpreted as a natural phenomenon associated with tree age or stand dynamics. Nor is it an artefact of comparing BAI chronologies of different lengths, as the phenomenon remains if the same analysis period of 26 years is compared across all sites (see 'Results' and Table 2). BAI at the LFL shows a strong negative relationship with mean annual temperature (Table 3) in agreement with the climate response reported for F. sylvatica from Turó de l'Home in the dendroecological study of Gutierrez (1988). The close correspondence of the declining BAI trend at the LFL with that of temperature recorded at the Turó de l'Home meteorological station (Fig. 4) shows that declining growth at the LFL may be closely linked to the rising temperatures of the Montseny region.

F. sylvatica is a masting species and seed production shows strong links with climate (Piovesan \& Adams, 2001). Despite the potential for reduced BAI in mast years, the close proximity of our sample sites to one another (Fig. 1) suggests that the decline in BAI at the LFL cannot be adequately explained by increased masting frequency in this region. Growth of F. sylvatica at low altitudes at Turó de l'Home is limited by high growing-season temperatures and promoted by high precipitation during the growing season (Gutierrez, 1988; A. S. Jump et al., unpublished). This is consistent with the high sensitivity of this species to drought (Gutierrez, 1988; Dittmar et al., 2003; Lebourgeois et al., 2005) and in part explains the climate-growth responses seen in Fig. 4 and Table 3. Furthermore, in parallel with recent warming, positive effects of high precipitation appear to have declined relative to the negative effects of temperature in recent years (Fig. 4, A. S. Jump et al., unpublished). The susceptibility of F. sylvatica to extreme temperatures increases with decreasing soil water availability (Lebourgeois et al., 2005), which is a likely consequence of increasing temperature

Table 1 Summary information for Fagus sylvatica samples used in this study

\begin{tabular}{lllllll}
\hline Site & $\begin{array}{l}\text { Stand basal } \\
\text { area }\left(\mathrm{m}^{2} \mathrm{ha}^{-1}\right)\end{array}$ & $\begin{array}{l}\text { Leaf area } \\
\text { index }\end{array}$ & $\begin{array}{l}\text { Altitude } \\
\text { (ma.s.l.) }\end{array}$ & $N$ & DBH (cm) & Age (years) \\
\hline Upper treeline (HFL, high Fagus limit) & 23.98 & 4.06 & 1640 & 15 & $56.6(28.2-118.4)$ & $110.47(50-236)$ \\
Central forest area (CFA) & 25.24 & 4.30 & 1127 & 14 & $47.3(25.8-66.2)$ & $94.6(57-143)$ \\
Low Fagus limit (LFL) & 20.62 & 4.09 & 992 & 14 & $51.3(33.3-68.1)$ & $92.1(50-119)$ \\
\hline
\end{tabular}

Mean values for $\mathrm{DBH}$ and age are followed by the range in parentheses. DBH and age do not differ significantly between sites (Kruskal-Wallace test, $P>0.05$ ).

Altitude, mean sample altitude; $N$, number of trees analysed; $\mathrm{DBH}$, diameter at breast height; Age, age at breast height.

Table 2 Comparison of mature tree basal area increment (BAI) across common 26-year intervals

\begin{tabular}{|c|c|c|c|c|c|c|}
\hline \multirow[b]{3}{*}{ Site } & \multicolumn{4}{|c|}{ Linear BAI trend 1978-2003 } & & \\
\hline & \multicolumn{2}{|c|}{ Average chronology } & \multicolumn{2}{|c|}{ Individual chronologies } & \multicolumn{2}{|c|}{ Mean mature BAI $\left(\mathrm{cm}^{2}\right)$} \\
\hline & Slope & $\begin{array}{l}P \text { (linear } \\
\text { regression) }\end{array}$ & $\begin{array}{l}\text { Range of } \\
\text { slopes }\end{array}$ & Direction of slopes & 1978-2003 & $\begin{array}{l}\text { First } 26 \text { years of } \\
\text { mature period }\end{array}$ \\
\hline HFL & $-0.20(0.18)$ & 0.17 & $-2.04-1.14$ & $2[+], 10[\mathrm{NT}], 3[-]$ & $31.36^{\mathrm{a}}(1.09)$ & $31.36^{\mathrm{a}}(1.09)$ \\
\hline CFA & $-0.10(0.12)$ & 0.71 & $-1.24-0.34$ & $1[+], 10[\mathrm{NT}], 3[-]$ & $34.53^{\mathrm{a}}(1.61)$ & $34.53^{\mathrm{a}}(1.61)$ \\
\hline LFL & $-0.36(0.12)$ & $<0.001$ & $-1.58--0.26$ & $6[\mathrm{NT}], 8[-]$ & $21.50^{\mathrm{b}}(0.94)$ & $27.99^{\mathrm{b}}(1.09)$ \\
\hline
\end{tabular}

Sites abbreviated as in Table 1. Standard error is given in parentheses.

Direction of slopes: $[+] /[-]$, significant positive/negative trend at $P \leq 0.05 ;[N T]$, no significant trend $(P>0.05)$.

Mean mature BAI in each column followed by different letters differs significantly ( $t$-test comparisons, $P<0.05$ ).

For explanation of 26-year periods see text. 
Table 3 Correlation of Fagus sylvatica BAI with mean annual temperature and total annual precipitation in the current and previous year

\begin{tabular}{|c|c|c|c|c|c|}
\hline \multirow[b]{2}{*}{ Site } & \multirow[b]{2}{*}{ Period } & \multicolumn{2}{|l|}{ Previous year } & \multicolumn{2}{|l|}{ Current year } \\
\hline & & Temperature & Precipitation & Temperature & Precipitation \\
\hline HFL & 1978-2003 & $-0.09(0.66)$ & $-0.21(0.32)$ & $0.02(0.92)$ & $-0.13(0.53)$ \\
\hline CFA & 1978-2003 & $-0.27(0.40)$ & $-0.08(0.80)$ & $-0.01(0.97)$ & $0.11(0.73)$ \\
\hline LFL & 1978-2003 & $-0.61(0.001)$ & $0.27(0.18)$ & $-0.45(0.022)$ & $0.25(0.22)$ \\
\hline LFL & 1960-2003 & $-0.62(<0.001)$ & $0.42(0.004)$ & $-0.59(<0.001)$ & $0.43(0.004)$ \\
\hline
\end{tabular}

Sites abbreviated as in Table 1.

Climate-BAI correlations for the LFL site are given for the 1978-2003 interval common to all sites and for the full mature BAI chronology.

$P$ values are given in parentheses, significant correlations are presented in bold type.

HFL, high Fagus limit; CFA, central forest area; LFL, low Fagus limit; BAI, basal area increment.

but unaltered precipitation recorded for the Montseny region (Fig. 2). A reduction in days when fog is recorded at the Turó de l'Home meteorological station has accompanied warming temperatures (data not shown), which suggests that fogs should also be shifting to progressively higher altitudes and occurring less frequently at the LFL. Fog episodes may have a positive effect on the growth of F. sylvatica in Montseny (Bolòs, 1983; Gutierrez, 1988), although they are not essential for this species to persist (Peñuelas \& Boada, 2003). Unfortunately, we have no data on the occurrence and duration of fog episodes at the lower limits of the F. sylvatica forest.

\section{$B A I$ related to altitude}

Trees in the central forest area show a very similar response to climate to those of trees at lower altitudes (Gutierrez, 1988; A. S. Jump et al., unpublished). They show a comparably strong negative response to growing season temperatures, although precipitation at the CFA is not as limiting as at the LFL. Our CFA site is, on average, $135 \mathrm{~m}$ higher in altitude than the LFL - corresponding to an approximate temperature decrease of $0.69^{\circ} \mathrm{C}$ (from the altitudinal temperature lapse rate of $0.51^{\circ} \mathrm{C}$ per $100 \mathrm{~m}$ reported by Peñuelas \& Boada (2003) for Montseny). Given the increase in mean annual temperatures at Montseny shown in Fig. 2, mean annual temperatures at the LFL in 1975 should equal those experienced at the CFA approximately 12 years later. If calculated only on the basis of difference in altitude, this indicates that the growth decline that began at the LFL some 28 years ago should have been affecting this central area of $F$. sylvatica forest for approximately the last 16 years. The CFA site is located in a level area of forest around the Santa Fe River and has deeper soils than those of the steep northeast-facing slope of the LFL (see Bolòs, 1983). Lebourgeois et al. (2005) show that soil water deficits play a crucial role in limiting the growth of F. sylvatica and moderating the effects of high temperatures. Differences in soil water availability between the two sites may explain why growth of the CFA remains unchanged while it is declining rapidly at the LFL - an explanation supported by the lower importance of high precipitation in promoting growth in the central forest area. Based on temperature differences between sites, our data suggest any future increase in aridity could cause growth to decline over much larger areas of the F. sylvatica forest at Montseny. Further study of differences in soil hydrology between these two sites would be rewarding.

Paulsen et al. (2000) note that a reduction in radial growth approaching the upper treeline can be interpreted as a direct response to decreasing temperature with increasing elevation. In their study of Pinus cembra and Picea abies they found evidence for an historic altitude-dependent reduction in annual radial growth over a distance of $250 \mathrm{~m}$ altitude approaching the treeline in the European Alps. The expected reduction in growth toward the treeline suggests that mature tree BAI should be lower at the HFL than at the CFA some $500 \mathrm{~m}$ below. However, Paulsen et al. (2000) describe a major increase in the radial growth of trees at the alpine treeline since 1940 related to increased temperature, with current growth at the treeline now equal to that of trees at sites $250 \mathrm{~m}$ lower.

If temperature increases are responsible for decreasing BAI at the LFL in our study then we might expect recent temperature increases to have increased BAI at the HFL, as high temperatures are linked to high annual growth at this site. The CFA trees are our best indicator for the maximum BAI achievable for these forest sites as this site occurs on deeper soils away from the climatic extremes experienced at the forest's altitudinal margins. 
Current levels of mean BAI are similar for the CFA and HFL samples (Table 2) as are mean tree age and diameter at breast height (Table 1). As growth at the upper treeline is expected to be lower than at lower elevations (Paulsen et al., 2000), a recent increase in BAI at the HFL may have taken place. Unfortunately, as we have no evidence for historic mature tree levels of BAI at the HFL, our data do not currently allow us to assess whether any recent increase in growth at this site has occurred.

\section{Wider significance of F. sylvatica growth decline}

When considered alongside the high sensitivity of F. sylvatica to drought (Dittmar et al., 2003; Lebourgeois et al., 2005) and the recent increase in its sensitivity to temperature (A. S. Jump et al., unpublished), the data we present here demonstrate a dramatic growth decline at the LFL related to rising temperatures in the study region over the last half-century. Strikingly, in a study of old-growth F. sylvatica forest in the Central Apennines, Italy, Piovesan et al. (2005b) report a comparable growth decline of this species over the same period, which they suggest may be related to changes in climate. In their study, BAI drops from approximately $28 \mathrm{~cm}^{2}$ in 1975 to approximately $21 \mathrm{~cm}^{2}$ in 2000 - a fall of $25 \%$ over 25 years. Although Piovesan et al. (2005b) do not specifically investigate the relationship between climate and BAI in the studied population, previous work found positive effects of spring temperature and summer precipitation on F. sylvatica ring width in the same area over the period 1832-2000 (Piovesan et al., 2003). Throughout the Central Italian Apennines, low-frequency variation in ring width has been related to variation in the North Atlantic oscillation (Piovesan \& Schirone, 2000). Like the F. sylvatica forest we investigated, the forest studied by Piovesan et al. (2005b) is also from the Mediterranean region and close to the southern range-edge of this species' distribution. Growth of F. sylvatica is strongly drought limited across the southern region of its distribution (Gutierrez, 1988; Biondi, 1993; Biondi \& Visani, 1996; Dittmar et al., 2003; Piovesan et al., 2003, 2005a; Lebourgeois et al., 2005). The comparable fall in BAI reported by Piovesan et al. (2005b) suggests that this climate-related decline in the growth of F. sylvatica at the edge of its range in Montseny is not an isolated phenomenon, but may be occurring at the southern range edge of this species elsewhere in Europe.

F. sylvatica is an increasingly important species for European forestry (Dittmar et al., 2003) and therefore a highly significant species in terms of carbon sequestration (Bascietto et al., 2004). Recent climatic warming has increased the length of the growing season for many species in the Montseny region (Peñuelas et al., 2002), suggesting a positive growth response to recent climatic changes might be expected for F. sylvatica. Many studies in recent years describe increasing growth trends for F. sylvatica and other forest species throughout Europe, leading to the assumption that carbon sequestration by this species is increasing (Sabate et al., 2002; Dittmar et al., 2003; Bascietto et al., 2004 and references therein). Our results demonstrate that for some low-altitude and low-latitude populations the reverse may be true, with increasing temperatures resulting in recent and rapid decline of the growth of this species.

\section{Conclusions}

Previous work on F. sylvatica in the Montseny Mountains by Peñuelas \& Boada (2003) found evidence that this species may be in decline at low altitude range edge. The work that we present here shows that this decline is linked to a rapid and recent decrease in the growth of adult trees at the lower limit of this species' distribution. Growth at the lower limit of F. sylvatica in this region fell by $49 \%$ between 1975 and 2003 linked to recent climatic warming. Our evidence suggests that increasing temperatures are exacerbating drought, with the result that the positive effects of years with high annual precipitation are declining. We cannot predict the long-term growth response of the forest interior based on temperature alone, but our results indicate that only a small increase in aridity may decrease growth of this species over much larger areas. Determining whether more widespread growth decline of $F$. sylvatica is occurring at its southern range edge should be the focus of further research.

\section{Acknowledgements}

Alistair Jump received a Marie Curie Intra-European Fellowship from the European Union for project FOREST RISE (Contract MC-MEIF-CT-2003-501475) while conducting this research. Additional support was provided by the European Union (Contract 506675, ALARM), the Catalan Government (grant SGR200500312), the Spanish Government (grants REN2003-04871 and CGL2004-01402/BOS) and Fundación BBVA. We thank Josep Piñol, Pere Comes, Servei Meteorològic de Catalunya and Servicio Meteorológico Nacional de España for supplying climate data and Martí Boada, Jaume Terradas, Josep Maria Alcañiz, Teresa Mata, and Sònia Sánchez for additional information on the Montseny region. We are grateful to anonymous referees for their helpful comments on earlier versions of this manuscript.

\section{References}

Bascietto M, Cherubini P, Scarascia-Mugnozza G (2004) Tree rings from a European beech forest chronosequence are useful for detecting growth trends and carbon sequestration. Canadian Journal of Forest Research, 34, 481-492. 
Biondi F (1993) Climatic signals in tree rings of Fagus sylvatica L. from the Central Apennines, Italy. Acta Oecologica - International Journal of Ecology, 14, 57-71.

Biondi F, Visani S (1996) Recent developments in the analysis of an Italian tree-ring network with emphasis on European beech (Fagus sylvatica L.). In: Tree Rings, Environment and Humanity: Proceedings of the International Conference, Radiocarbon, 1996 (eds Dean JS, Meko DM, Swetnam TW), pp. 713-725. Tucson, Arizona.

Bolòs O (1983) La vegetació del Montseny. Diputació de Barcelona, Barcelona.

Brubaker LB (1986) Responses of tree populations to climatic change. Vegetation, 67, 119-130.

Cook E, Briffa K, Shiyatov S et al. (1990) Tree-ring standardization and growth-trend estimation. In: Methods of Dendrochronology: Applications in the Environmental Sciences (eds Cook ER, Kairiukstis LA), pp. 104-123. Kluwer Academic Publishers, Dordrecht, the Netherlands.

Dittmar C, Zech W, Elling W (2003) Growth variations of common beech (Fagus sylvatica L.) under different climatic and environmental conditions in Europe - a dendroecological study. Forest Ecology and Management, 173, 63-78.

Duchesne L, Ouimet R, Houle D (2002) Basal area growth of sugar maple in relation to acid deposition, stand health and soil nutrients. Journal of Environmental Quality, 31, 1676-1683.

Duchesne L, Ouimet R, Morneau C (2003) Assessment of sugar maple health based on basal area growth pattern. Canadian Journal of Forest Research, 33, 2074-2080.

Durbin J, Watson GS (1951) Testing for serial correlation in least squares regression, II. Biometrika, 30, 159-178.

Fekedulegn D, Hicks RR, Colbert JJ (2003) Influence of topographic aspect, precipitation and drought on radial growth of four major tree species in an Appalachian watershed. Forest Ecology and Management, 177, 409-425.

Grace J, Berninger F, Nagy L (2002) Impacts of climate change on the tree line. Annals of Botany, 90, 537-544.

Gutierrez E (1988) Dendroecological study of Fagus sylvatica L. in the Montseny Mountains (Spain). Acta Oecologica - Oecologia Plantarum, 9, 301-309.

Hogg EH, Brandt JP, Kochtubajda B (2002) Growth and dieback of Aspen forests in northwestern Alberta, Canada, in relation to climate and insects. Canadian Journal of Forest Research, 32, 823-832.

Holmes RL (2001) Dendrochronology program library. Available from the Laboratory of Tree Ring Research, University of Arizona, Tucson, AR, USA. http://www.ltrr.arizona.edu/software.html

Jalas J, Suominen J (1976) Atlas Florae Europaea 3: Salicaceae to Balanophoraceae. Cambridge University Press, Cambridge, UK.

Kullman L (2002) Rapid recent range-margin rise of tree and shrub species in the Swedish Scandes. Journal of Ecology, 90, 68-77.

Kullman L (2003) Recent reversal of Neoglacial climate cooling trend in the Swedish Scandes as evidenced by mountain birch tree-limit rise. Global and Planetary Change, 36, 77-88.

LaMarche VC Jr. (1973) Holocene climatic variations inferred from treeline fluctuations in the White Mountains, California. Quaternary Research, 3, 632-660.
Larsson L-A (2003a) CooRecorder: image co-ordinate recording program. Available at http://www.cybis.se.

Larsson L-A (2003b) CDendro: Cybis Dendro dating program. Available at http://www.cybis.se.

LeBlanc DC (1990a) Red spruce decline on Whiteface Mountain, New York. I. Relationships with elevation, tree age and competition. Canadian Journal of Forest Research, 20, 1408-1414.

LeBlanc DC (1990b) Relationships between breast-height and whole-stem growth indices for red spruce on Whiteface mountain, New York. Canadian Journal of Forest Research, 20, 1399-1407.

LeBlanc DC, Nicholas NS, Zedaker SM (1992) Prevalence of individual-tree growth decline in red spruce populations of the southern Appalachian mountains. Canadian Journal of Forest Research, 22, 905-914.

Lebourgeois FL, Bréda N, Ulrich E et al. (2005) Climate-treegrowth relationships of European beech (Fagus sylvatica L.) in the French Permanent Plot Network (RENECOFOR). Trees, 19, 385-401.

Lloyd AH (1997) Response of tree-line populations of foxtail pine (Pinus balfouriana) to climate variation over the last 1000 years. Canadian Journal of Forest Research, 27, 936-942.

Lloyd AH, Fastie CL (2003) Recent changes in treeline forest distribution and structure in interior Alaska. Ecoscience, 10, 176-185.

Makinen H, Nojd P, Kahle HP et al. (2002) Radial growth variation of Norway spruce (Picea abies (L.) Karst.) across latitudinal and altitudinal gradients in central and northern Europe. Forest Ecology and Management, 171, 243-259.

Meshinev T, Apostolova I, Koleva E (2000) Influence of warming on timberline rising: a case study on Pinus peuce Griseb. in Bulgaria. Phytocoenologia, 30, 431-438.

Muzika RM, Guyette RP, Zielonka Tet al. (2004) The influence of $\mathrm{O}_{3}, \mathrm{NO}_{2}$ and $\mathrm{SO}_{2}$ on growth of Picea abies and Fagus sylvatica in the Carpathian mountains. Environmental Pollution, 130, 65-71.

Paulsen J, Weber UM, Korner C (2000) Tree growth near treeline: abrupt or gradual reduction with altitude? Arctic Antarctic and Alpine Research, 32, 14-20.

Pedersen BS (1998) The role of stress in the mortality of Midwestern oaks as indicated by growth prior to death. Ecology, 79, 79-93.

Peñuelas J, Boada M (2003) A global change-induced biome shift in the Montseny Mountains (NE Spain). Global Change Biology, 9, 131-140.

Peñuelas J, Filella I, Comas P (2002) Changed plant and animal life cycles from 1952 to 2000 in the Mediterranean region. Global Change Biology, 8, 531-544.

Phipps RL, Whiton JC (1988) Decline in long-term growth trends of white oak. Canadian Journal of Forestry Research, 18, 24-32.

Pigott CD, Huntley JP (1978) Factors controlling the distribution of Tilia cordata at the northern limits of its geographical range. New Phytologist, 81, 429-441.

Piovesan G, Adams JM (2001) Masting behaviour in beech: linking reproduction and climatic variation. Canadian Journal of Botany, 79, 1039-1047.

Piovesan G, Bernabei M, Di Filippo A et al. (2003) A long-term tree ring beech chronology from a high-elevation old growth forest of Central Italy. Dendrochronologia, 21, 13-22. 
Piovesan G, Biondi F, Bernabei M et al. (2005a) Spatial and altitudinal bioclimatic zones of the Italian peninsula identified from a beech (Fagus sylvatica L.) tree- ring network. Acta Oecologica - International Journal of Ecology, 27, 197-210.

Piovesan G, Di Filippo A, Alessandrini A et al. (2005b) Structure, dynamics and dendroecology of an old-growth Fagus forest in the Apennines. Journal of Vegetation Science, 16, 13-28.

Piovesan G, Schirone B (2000) Winter North Atlantic oscillation effects on the tree rings of the Italian beech (Fagus sylvatica L.). International Journal of Biometeorology, 44, 121-127.

Quenouille MH (1952) Associated Measurements. Butterworth Scientific, London.

Sabaté S, Gracia CA, Sánchez A (2002) Likely effects of climate change on growth of Quercus ilex, Pinus halepensis, Pinus pinaster, Pinus sylvestris and Fagus sylvatica forests in the Mediterranean region. Forest Ecology and Management, 162, 23-37.

Sanz-Elorza M, Dana ED, Gonzalez A et al. (2003) Changes in the high mountain vegetation of the Central Iberian Peninsula as a probable sign of global warming. Annals of Botany, 92, 273-280.

Sturm M, Racine C, Tape K (2001) Climate change: increasing shrub abundance in the Arctic. Nature, 411, 546-547.

Takahashi K, Homma K, Shiraiwa T et al. (2001) Climatic factors affecting the growth of Larix cajenderi in the Kamchatka Peninsula, Russia. Eurasian Journal of Forest Research, 3, 1-9.

Wardle P, Coleman MC (1992) Evidence for rising upper limits of 4 native New Zealand forest trees. New Zealand Journal of Botany, 30, 303-314. 